\section{Impacted gastroscope in the esophagus}

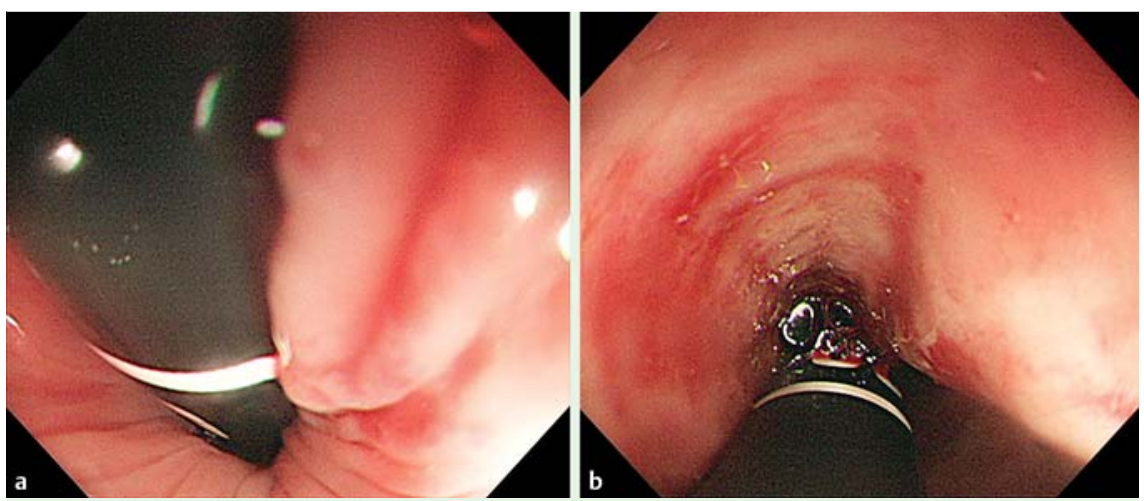

Fig. 1 An 81-year-old woman with hypertension was treated with esophagogastroduodenoscopy; several attempts were made to intubate the duodenum. a The scope slipped back into the esophagus as it retroflexed. b Retroflexed view showing 30-cm length marker.

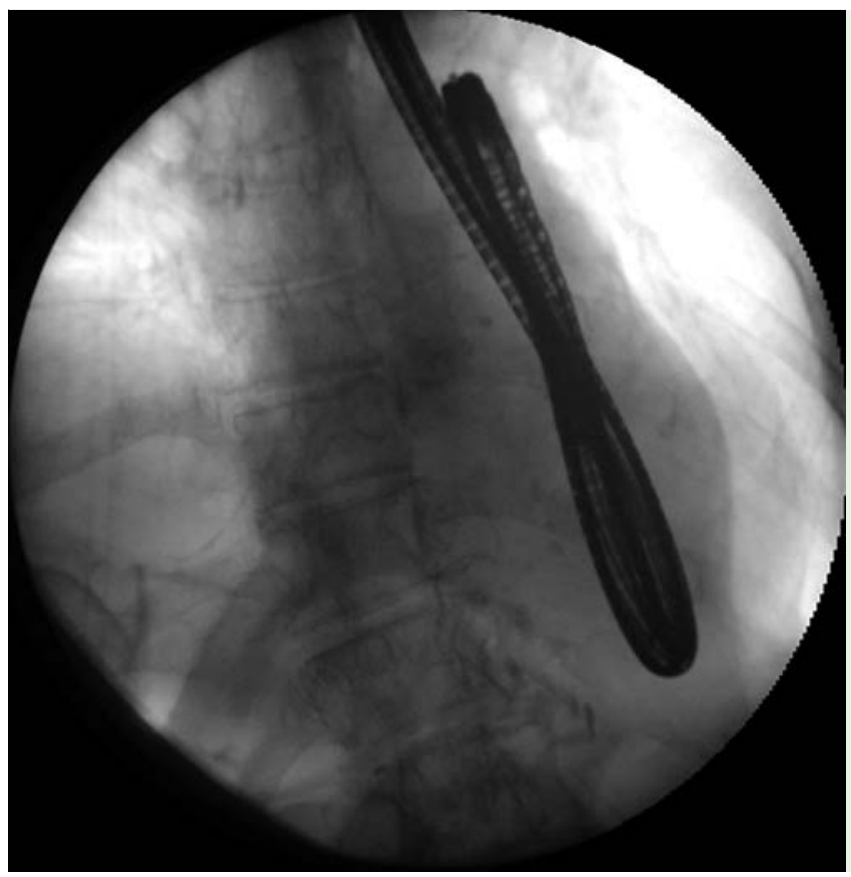

Fig. 2 During esophagogastroduodenoscopy in an 81-year-old woman, fluoroscopy showed that the tip of the scope was acutely angulated with distortion and impacted in the lower esophagus.

An 81-year-old woman with hypertension was admitted to our hospital. Because she had been suffering from persistent nausea, esophagogastroduodenoscopy was performed. During the procedure, a large hiatal hernia was identified, and the scope was successfully introduced into the distal stomach. After several attempts to intubate the duodenum, the scope slipped back into the esophagus as it retroflexed and resisted straightening ( $\bullet$ Fig. 1 a), and a strong resistance was felt immediately. We attempted unsuccessfully to move the

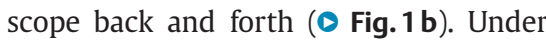

fluoroscopy, the tip of the scope was confirmed to be acutely angulated with distortion and impacted in the lower esophagus (๑ Fig.2). The retroflexed scope was withdrawn slowly under fluoroscopy and removed successfully in this position. Subsequent esophagoscopy showed a shallow trauma in the lower esophagus, but computed tomography of the chest and neck revealed no air density in the soft tissue. Some cases of endoscope impaction have been reported in the literature [1 - 3], and they tend to occur in a hiatal hernia sac [1]. Kavin and Schneider withdrew the instrument by pulling both the distal and proximal ends at the same time under X-ray guidance, which is the same as the method we used. Pregun and colleagues reported their experience with a doubled-back endoscope in the esophagus. The endoscope was straightened in the stomach under laparotomy [3].

This rare adverse event must be considered prior to retroflexion in patients with a large hiatal hernia, gastric remnant, or deformed stomach.

Endoscopy_UCTN_Code_CPL_1AH_2AB

Competing interests: None

Yoshitaka Imoto ${ }^{1}$, Toshi Takaoka ${ }^{1}$, Naoki Muguruma², Satoshi Teramae', Hirohiko Shinomiya', Satoshi Wada', Tetsuji Takayama²

${ }^{1}$ Department of Gastroenterology, Oe Kyoudou Hospital, Yoshinegawa city, Japan

2 Department of Gastroenterology and Oncology, The University of Tokushima Graduate School, Tokushima city, Japan

\section{References}

1 Kavin H, Schneider J. Impaction of a fibreoptic gastroscope in the oesophagus: an unusual complication of gastroscopy. S Afr Med J 1970; 44: 478 - 479

2 Braucher RE, Kirsner JB. Case report: impacted fiberscope. Gastrointest Endosc 1965; 12: $20-21$

3 Pregun I, Zágoni T, Péter A et al. Rare complication of upper gastrointestinal endoscopy: doubled-back endoscope in the esophagus. Endoscopy 2008; 40 (Suppl. 02): E48

Bibliography

Dol http://dx.doi.org/

10.1055/s-0034-1377595

Endoscopy 2014; 46: E523

(C) Georg Thieme Verlag KG

Stuttgart · New York

ISSN 0013-726X

\section{Corresponding author}

\section{Naoki Muguruma, MD, PhD}

Department of Gastroenterology and Oncology

The University of Tokushima Graduate School

3-18-15

Kuramoto-cho

Tokushima city

770-8503

Japan

Fax: +81-88-6339235

muguruma.clin.med@gmail.com 